CASO CLÍNICO

\title{
Leiomiosarcoma suprarrenal y cáncer cervicouterino sincrónicos. Reporte de caso y revisión de la literatura
}

\author{
Fernando Silva-Benito ${ }^{*}$, Juan Manuel Medina-Castro², Carlos López-Zavala², Axel Costilla-Montero ${ }^{3}$ y \\ David Eduardo Aguirre-Quezada ${ }^{4}$
}

${ }^{1}$ Médico residente de $3 .{ }^{\text {er }}$ año de Cirugía Oncológica; ${ }^{2}$ Médico adscrito al Área de Tumores Ginecológicos del Centro Oncológico Estatal; ${ }^{3}$ Urólogo adscrito al Área de Tumores urológicos del Centro Oncológico Estatal; ${ }^{4}$ Médico adscrito al área de Patología de Centro Oncológico Estatal, Toluca de Lerdo, México

\section{Resumen}

El leiomiosarcoma suprarrenal (LMS) primario y el carcinoma cervicouterino raramente se presentan de forma conjunta. Presentamos el caso de una mujer de 72 años de edad con esta enfermedad, el tratamiento y los hallazgos por patología. El LMS fue encontrado incidentalmente en estudio de extensión. Se realizó resección completa de la lesión suprarrenal, que mostró inmunorreacciones positivas a actina de músculo liso y a desmina. El cáncer cervicouterino se trató con radioterapia y quimioterapia concomitante. La paciente lleva un periodo libre de enfermedad (PLE) de 17 meses, sin recurrencia. Se sostiene que la resección quirúrgica completa del LMS es el tratamiento más importante.

Palabras clave: Leiomiosarcoma suprarrenal. Cáncer cervicouterino. Adrenalectomía.

\section{Adrenal leiomyosarcoma and synchronous cervical cancer. Case report and literature review}

\begin{abstract}
Primary adrenal leiomyosarcoma (LMS) and synchronous cervical carcinoma are rare. We present the case of a 72-year-old woman with this disease, treatment and findings by pathology. The LMS was found incidentally in an extension study. Complete resection of the adrenal lesion was performed, showing positive immunoreactions to smooth muscle actin and desmin. Cervical cancer was treated with radiotherapy and concomitant chemotherapy. She has a disease-free period of 17 months, with no recurrence. It is argued that complete surgical resection of LMS is the most important treatment.
\end{abstract}

Key words: Adrenal leiomyosarcoma. Cervical cancer. Adrenalectomy.

\section{Correspondencia:}

${ }^{\star}$ F. Silva Benito

E-mail: fernan2785@ hotmail.com
Disponible en internet: 13-05-2019 Gac Mex Oncol. 2019;Supp 18:69-74

www.gamo-smeo.com 1665-9201/@ 2018 Sociedad Mexicana de Oncología. Publicado por Permanyer México SA de CV. Este es un artículo Open Access bajo la licencia CC BY-NC-ND (http://creativecommons.org/licenses/by-nc-nd/4.0/). 


\section{Introducción}

El LMS primario es una neoplasia de tejidos blandos muy rara originada en el músculo liso de los vasos, cuya incidencia va del 0.1 al $0.2 \%$ de los tumores malignos de tejidos blandos intraabdominales en adultos de forma general $^{1,2}$. En este trabajo presentamos el caso raro de una paciente que cursa con cáncer cervicouterino y en la cual durante el estudio de extensión incidentalmente se encontró un segundo primario, un LMS izquierdo, lo que hace interesante este caso en particular. Es el caso número 32 de reportes de LMS primario en la literatura mundial y el primero reportado como sincrónico de suprarrenal y cervicouterino (Tabla 1).

\section{Presentación del caso}

Paciente femenino de 72 años de edad con antecedentes heredofamiliares: madre y un hermano con cáncer gástrico y dos tíos con cáncer de páncreas. Alérgica a penicilina. Hipertensión arterial sistémica de tres años de evolución.

Antecedentes ginecoobstétricos: Menarquía a los 15 años, con ritmo $28 \times 6$; inicio de vida sexual activa a los 20 años; número de parejas sexuales, una; ocho gestaciones, seis partos y dos abortos; climaterio a los 50 años.

Inicia su padecimiento actual en diciembre de 2014 con sangrado transvaginal escaso que ha aumentado de intensidad. Acude a médico privado, quien indica citología de cérvix, diagnosticándose adenocarcinoma de endometrio en mayo de 2015.

Exploración física: puntuación en la escala del Eastern Cooperative Oncology Group, 0; cabeza y cuello sin alteración; tórax y abdomen sin alteración; en relación a los genitales, presenta vulva sin alteración, vagina de paredes elásticas, cérvix posterior móvil y tumor palpable de $4 \mathrm{~cm}$ con bordes irregulares en radio de las 2 en borde inferior del cérvix, se palpan nódulos en la pared posterior de la vagina de $1 \mathrm{~cm}$, parametrio izquierdo acortado sin llegar a la pared pélvica; tacto rectal con compresión extrínseca.

En la tomografía computarizada (TC), como estudio de extensión, se encuentra lesión heterogénea en glándula suprarrenal izquierda (Fig. 1A) y tumor de cérvix que infiltra el parametrio izquierdo (Fig. 1B).

Para descartar un tumor adrenal funcional se evalúan metanefrinas urinarias, catecolaminas en suero, urinarias y aldosterona, las cuales se encuentran normales. El Papanicolaou realizado de forma externa había reportado hiperplasia o adenocarcinoma de endometrio.

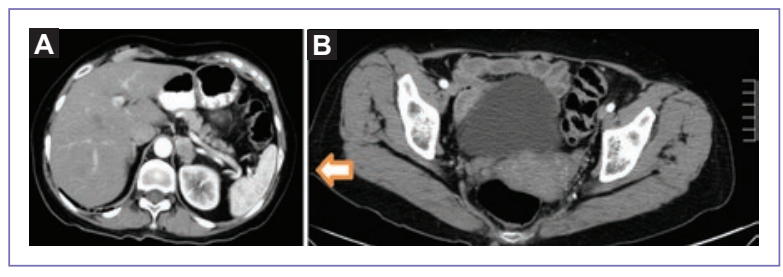

Figura 1. TC de abdomen fase arterial (12 de mayo de 2015). A: Lesión heterogénea en glándula suprarrenal izquierda con características de malignidad (flecha). B: Tumor cervical de $35 \times 23 \mathrm{~cm}$ con datos de infiltración de parametrio izquierdo y tercio proximal de la vagina (flecha).

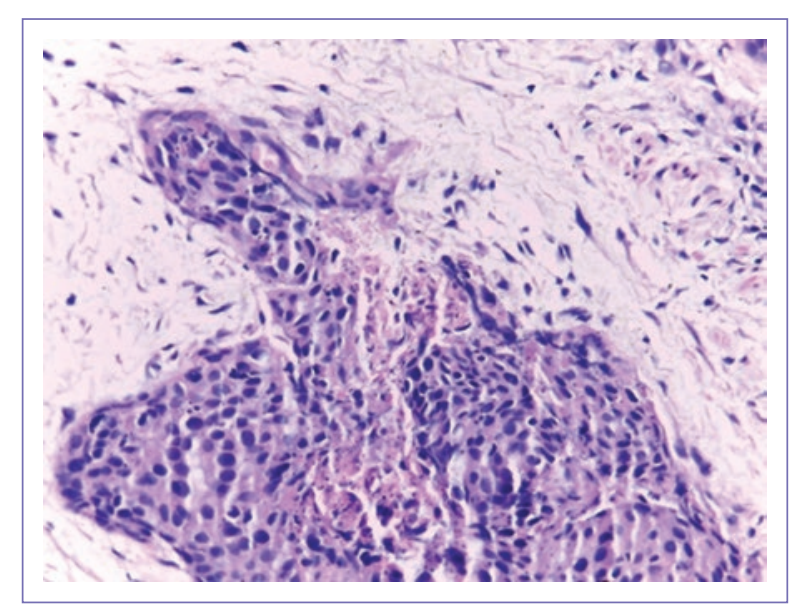

Figura 2. Laminilla de revisión de biopsia cervical: carcinoma epidermoide invasor de células grandes no queratinizantes de cérvix.

Biopsia de cérvix realizada fuera de nuestra unidad en mayo de 2015 y reportada como carcinoma epidermoide moderadamente diferenciado, no queratinizante de células grandes, invasor de cérvix, con una revisión de laminillas realizada en nuestra unidad que reporta carcinoma epidermoide invasor de células grandes no queratinizantes de cérvix (Fig. 2).

La paciente se valora por unidad funcional de tumores ginecológicos, integrando el diagnóstico de cáncer cervicouterino EC IIB, cuyo tratamiento iniciaría tras concluir el tratamiento de la enfermedad suprarrenal.

En junio de 2015 se decide suprarrenalectomía izquierda laparoscópica por urología, con hallazgos de tumor suprarrenal izquierdo de aproximadamente $3 \mathrm{x}$ $3 \mathrm{~cm}$, de bordes irregulares, sólido y sin afección a estructuras adyacentes (Fig. 3). El estudio histopatológico de la pieza quirúrgica reportó LMS con inmunorreacciones positivas a anticuerpos antimúsculo liso, desmina y Ki67 (20\%) (Fig. 4), negatividad a PS-100 y CKAE1/3 (Fig. 5), con infiltración a tejido adiposo con tumor en superficie quirúrgica entintada y sin permeación linfovascular evidente. 


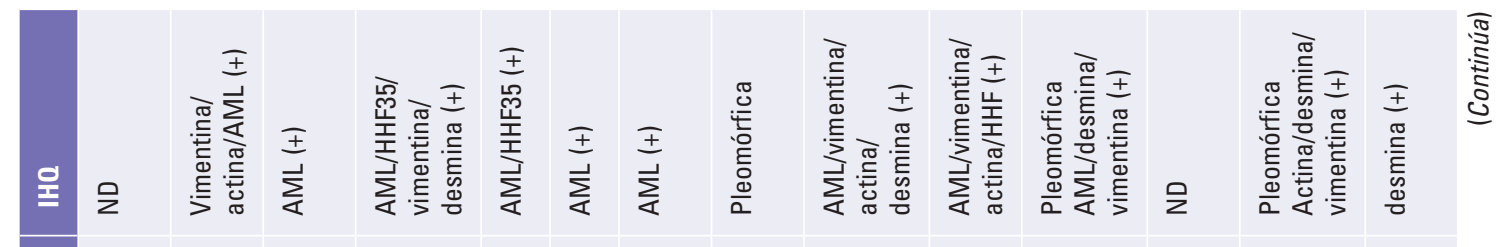
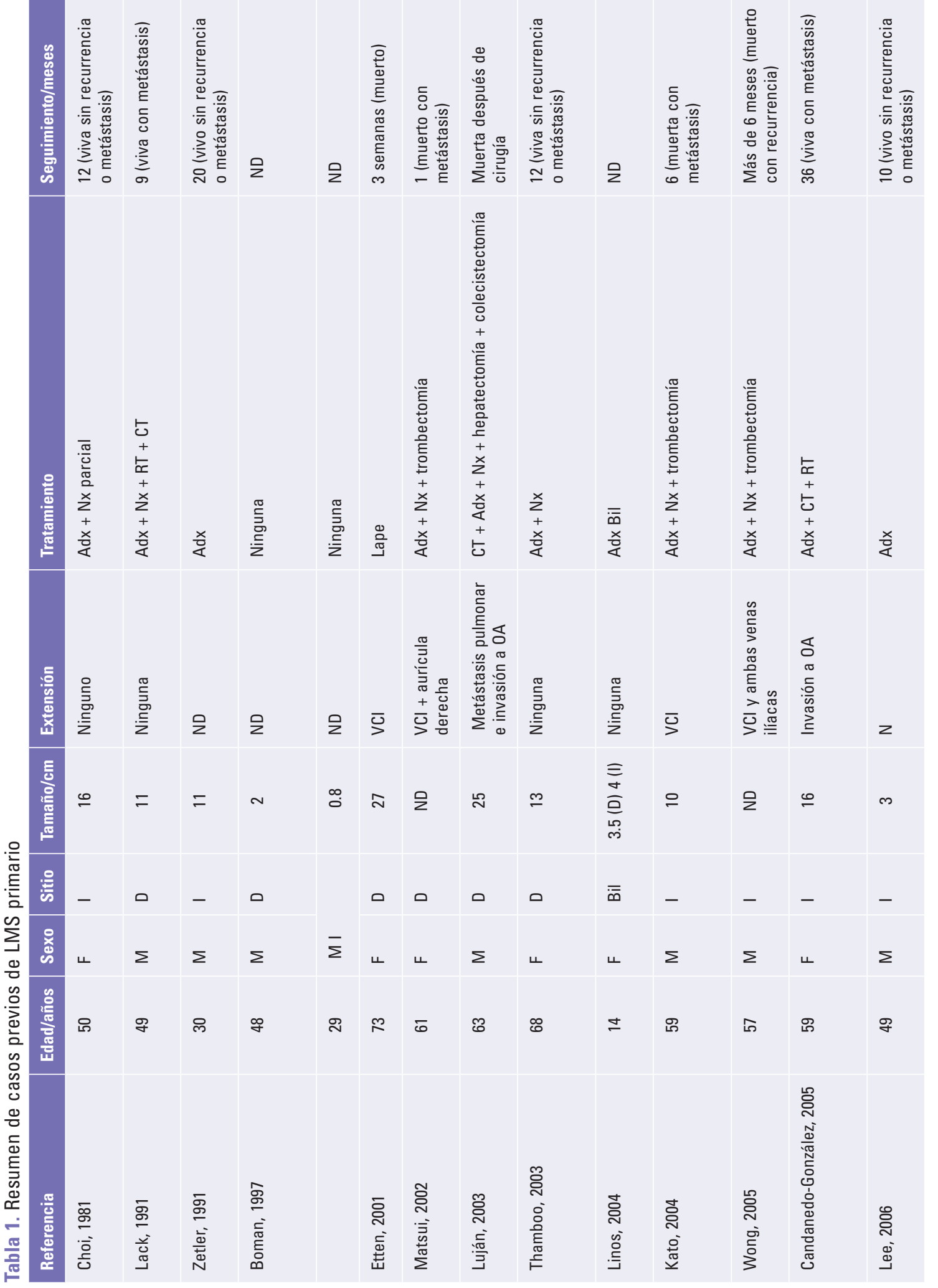

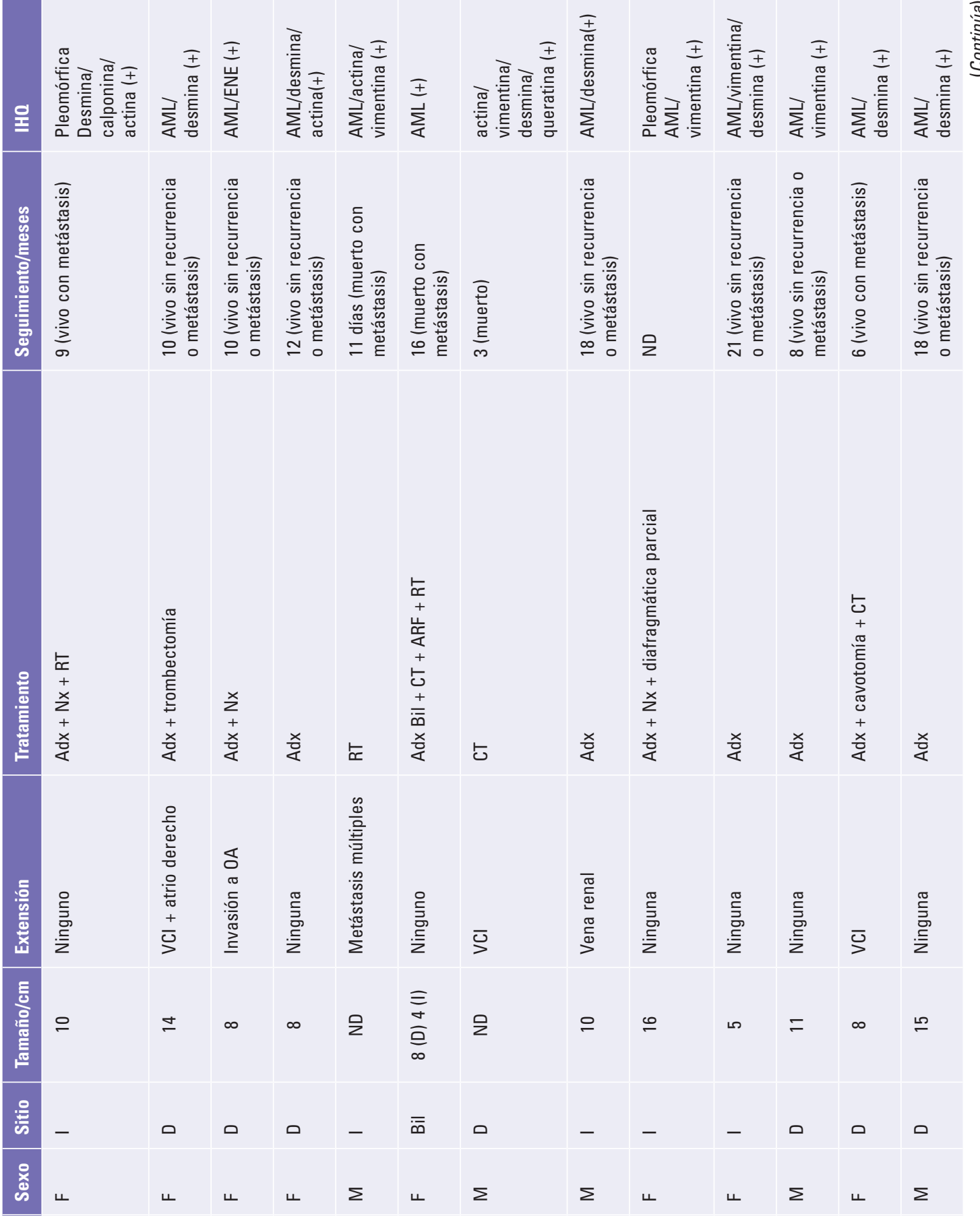

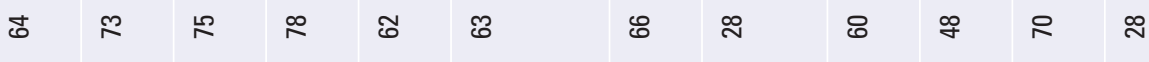

哭 㩆

क

胥

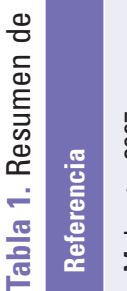

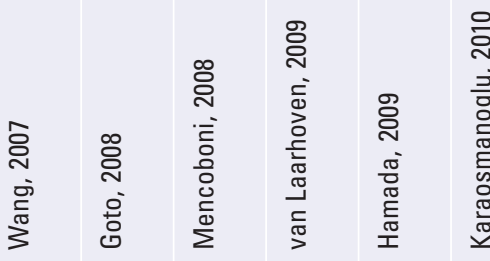

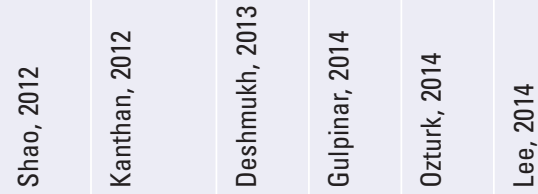




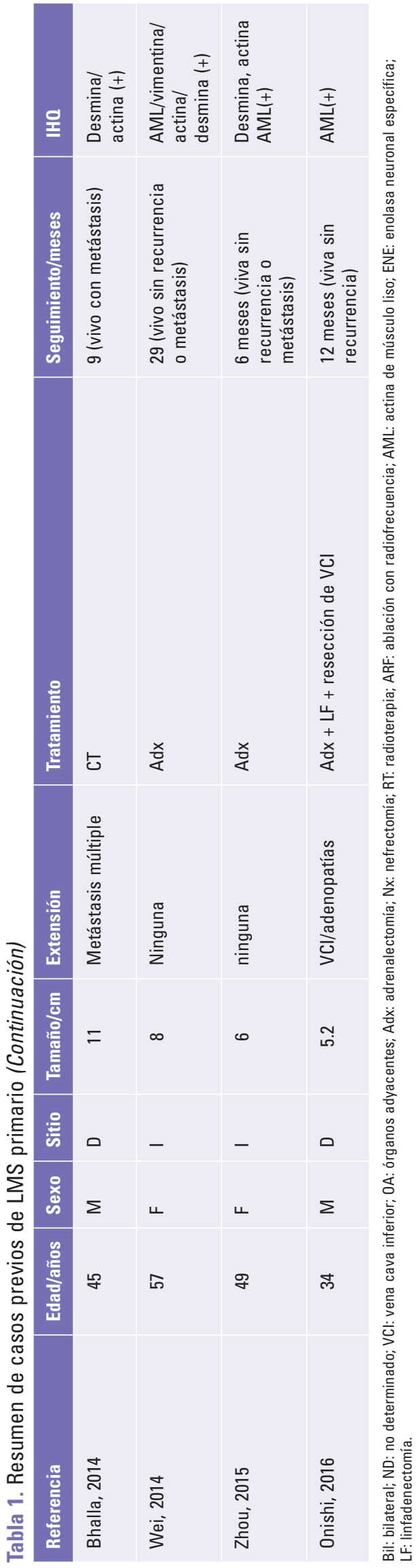

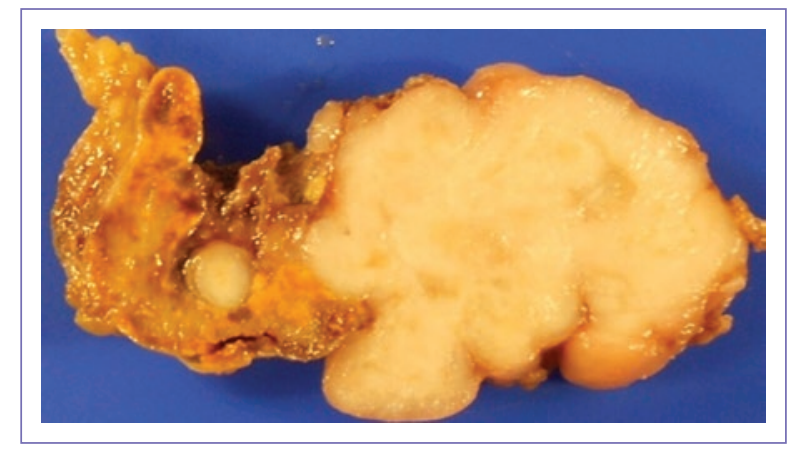

Figura 3. Tumor suprarrenal izquierdo de aproximadamente $3 \times 3 \mathrm{~cm}$, de bordes irregulares, sólido.

Para el tratamiento del cáncer cervicouterino recibió radioterapia a pelvis 50 Gy dividida en 25 fracciones (desde el 2 de mayo hasta el 19 de octubre de 2015) con quimioterapia concomitante con cisplatino (112 mg) (dos ciclos) y carboplatino $625 \mathrm{mg}$ (un ciclo) (desde el 7 de septiembre hasta el 23 de octubre de 2015) y, al finalizar, braquiterapia con alta tasa de dosis, 22.5 Gy EQD2 (dosis biológica efectiva): 79.3 Gy, presentando toxicidad leve. Durante el seguimiento se realiza TC de control, sin evidencia de actividad tumoral, y se inicia vigilancia.

\section{Discusión}

El primer caso de LMS fue descrito en 1981 por Choi y Liu, que reportaron un leiomiosarcoma de $12 \mathrm{~cm}$ que surgía de la vena suprarrenal izquierda ${ }^{3,4}$. El leiomiosarcoma es una neoplasia de tejidos blandos que puede surgir de cualquier estructura u órgano que contiene músculo liso ${ }^{5}$, aunque surge principalmente en retroperitoneo y cavidad abdominal ${ }^{5-7}$. El leiomiosarcoma de la glándula suprarrenal es muy poco frecuente ${ }^{5-7}$. Muy probablemente surja del músculo liso de la vena central 0 sus tributarias ${ }^{1,5-7}$. Se han reportado 31 casos en la literatura mundial hasta la fecha en inglés ( $v$. Tabla 1$)^{1,8}$.

En la mayoría de los casos se trata de pacientes ancianos y con tumores grandes, que inician con un cuadro de dolor abdominal. En el caso de nuestra paciente, el hallazgo del tumor suprarrenal fue incidental por estudio de extensión del tumor cervical; la paciente solo refirió sintomatología del tumor cervical. Los leiomiosarcomas se presentan en la misma proporción en hombres y mujeres, y en la glándula suprarrenal derecha y en la izquierda. La mayoría de los casos son de tipo convencional y solo cinco son de variedad pleomórfica'. Se han reportados casos asociados a infección por el virus de inmunodeficiencia humana y el virus de Epstein Barr, pero no hay evidencia sólida de la patogénesis de estos virus. 


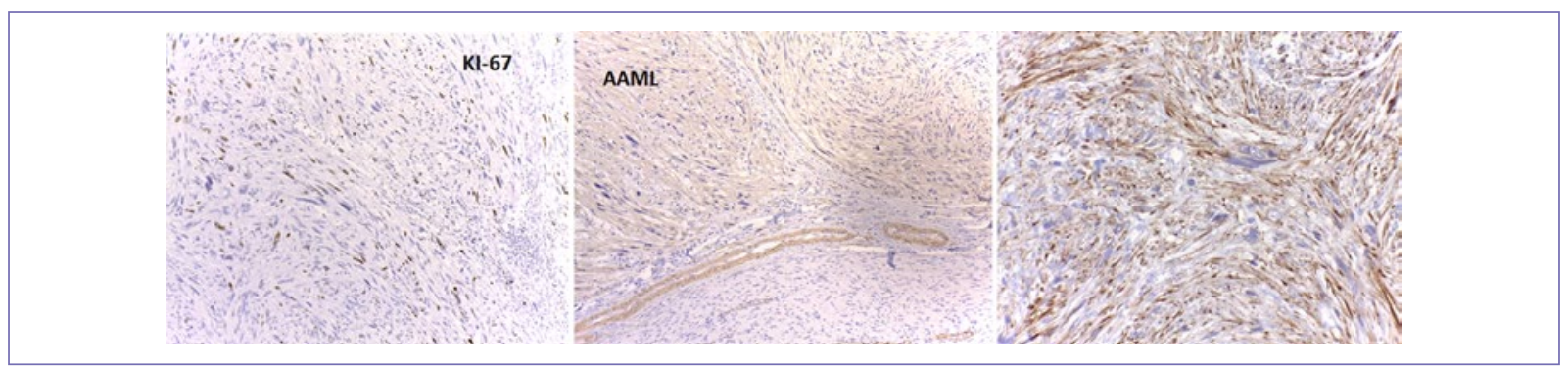

Figure 4. Inmunoreactividad positiva para Ki-67(20\%), AAML y Desmina.

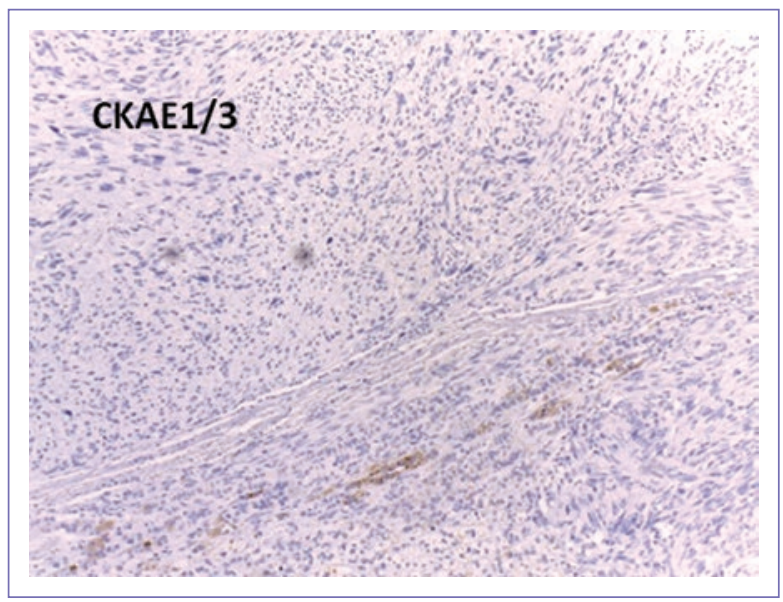

Figure 5. Inmunoreactividad negativa para CKAE1/.

No existe un marcador tumoral aplicable o característica por imagen disponible para hacer el diagnóstico preoperatorio y todos los casos reportados fueron diagnosticados después de la cirugía o en la necropsia'.

La evaluación histopatológica e inmunohistoquímica es indispensable, no solo para determinar el tipo de tumor sino también para el diagnóstico diferencial. Los leiomiosarcomas convencionales muestran inmunorreactividad fuerte para marcadores de músculo liso, como la actina de músculo liso y/o la actina específica de músculo liso en el 90 al $95 \%$ de los casos, y desmina en el 70 al $90 \%$ de los casos ${ }^{1}$, como sucedió en nuestro caso con actina y desmina positivas para músculo liso con Ki67 del 20\%.

La cirugía es el pilar del tratamiento, pero el pronóstico para los pacientes con LMS no es predecible. El caso de mayor supervivencia es de 36 meses con metástasis ${ }^{2}$ y el segundo, de 29 meses con una recurrencia local resecada a los 17 meses? $^{7}$.

La paciente de nuestro caso lleva un PLE de 20 meses y lo que motiva este reporte especial es la presentación sincrónica del cáncer cervicouterino, cuyo pronóstico es del $58 \%$ a cinco años ${ }^{9}$. Se consideró que el pronóstico estaba condicionado primero por el tumor suprarrenal y se decidió dar tratamiento a este último. Posteriormente se estableció el tratamiento del cáncer cervical con quimioterapia y radioterapia concomitante de acuerdo con las guías de tratamiento internacional ${ }^{10}$.

Hasta la fecha este es el primer caso reportado en la literatura mundial como LMS y cáncer cervicouterino sincrónico. La paciente no ha sufrido recaída hasta la fecha y los estudios de control por imagen son negativos a actividad tumoral locorregional y a distancia.

\section{Conflicto de intereses}

Los autores de este trabajo declaran no tener conflictos de intereses para la elaboración de este artículo.

\section{Agradecimientos}

Este trabajo fue apoyado por el Departamento de Investigación del Centro Oncológico Estatal.

\section{Bibliografía}

1. Zhou Y, Tang Y, Tang J, Deng F, Gong G, Dai Y. Primary adrenal leiomyosarcoma: a case report and review of literature. Int J Clin Exp Pathol. 2015;8(4):4258-63.

2. Candanedo-González FA, Vela Chávez T, Cerbulo-Vazquez A. Pleomorphic leiomyosarcoma of the adrenal gland with osteoclast-like giant cells. Endocr Pathol. 2005;16:75-81.

3. Wang TS, Ocal IT, Salem RR, Elefteriades J, Sosa JA. Leiomyosarcoma of the adrenal vein: a novel approach to surgical resection. World J Surg Oncol. 2007;5:109.

4. Tomasich FD, Luz Mde A, Kato M, Targa GZ, Dias LA, Zucoloto FJ, Ogata DC. [Primary adrenal leiomyosarcoma]. Arq Bras Endocrinol Metabol. 2008;52(9):1510-4.

5. Deshmukh SD, Babanagare SV, Anand M, Pande DP, Yavalkar P. Primary adrenal leiomyosarcoma: a case report with immunohistochemical study and review of literature. J Cancer Res Ther. 2013;9(1):114-6.

6. Shao IH, Lee WC, Chen TD, Chiang YJ. Leiomyosarcoma of the adrenal vein. Chang Gung Med J. 2012;35(5):428-31.

7. Wei J, Sun A, Tao J, Wang C, Liu F. Primary adrenal leiomyosarcoma: case report and review of the literature. Int J Surg Pathol. 2014;22(8):722-6.

8. Onishi T, Yanagihara Y, Kikugawa T, Miura N, Noda T, Kakuda T, et al. Primary adrenal leiomyosarcoma with lymph node metástasis: a case report. World J Surg Oncol. 2016;14(1):176.

9. Edge SB, Byrd B, Compton CC, Fritz AG, Greene F, Trotti A. (Eds.). AJCC Cancer Staging Manual, $7^{\text {th }}$ Ed. New York: Springer; 2010.

10. National Comprehensive Cancer Network. Cervical Cáncer. In: NCCN clinical practice guidelines in oncology. Version 1. Fort Washington: National Comprehensive Cancer Network; 2016. 